\title{
INFLUÊNCIA DA SECAGEM DA CASCA DE ABACAXI NA ACEITAÇÃO SENSORIAL DO CHÁ PARA OBTENÇÃO DE CO- PRODUTO DE ABACAXI
}

\author{
A. S. B. OLIVEIRA ${ }^{1}$, S. B. ALMEIDA ${ }^{1}$, L. P. MUSSI $^{1}$ e N. R. PEREIRA ${ }^{1}$ \\ ${ }^{1}$ Universidade Estadual do Norte Fluminense Darcy Ribeiro, Centro de Ciências e Tecnologias \\ Agropecuárias \\ E-mail para contato: nadiar@uenf.br
}

\begin{abstract}
RESUMO - Este trabalho aborda a obtenção de um co-produto de abacaxi por meio do estudo da secagem da casca do fruto para obtenção de matéria prima para produção de chá. Os objetivos foram avaliar os efeitos da temperatura e velocidade do ar na secagem da casca de abacaxi em secador de leito fluidizado e na aceitação sensorial do chá. $\mathrm{O}$ processo de secagem seguiu um planejamento experimental $2^{2}$ com três repetições no ponto central, cujas variáveis independentes foram temperatura $\left(70\right.$ a $\left.90{ }^{\circ} \mathrm{C}\right)$ e velocidade do ar $(8$ a $10 \mathrm{~m} / \mathrm{s})$. O chá foi preparado por infusão a $100{ }^{\circ} \mathrm{C}$, sendo avaliado por teste de aceitação por 63 consumidores quanto à impressão global, cor, aroma e sabor, utilizando a escala hedônica estruturada de nove pontos. A temperatura do ar apresentou efeito negativo significativo sobre a umidade final do produto seco, ao nível de $95 \%$ de confiança, que atingiu teores entre $3 \%$ e $10 \%$ após 90 minutos de secagem. Nenhum dos atributos sensoriais avaliados sofreu efeito significativo pelas variáveis independentes, a 95\% de confiança. Contudo, os resultados da aceitação sensorial indicaram que todas as formulações de chá elaboradas foram bem apreciadas pelos consumidores, apresentando médias hedônicas próximas a "gostei moderadamente" para impressão global, cor e aroma e acima de "gostei ligeiramente" para o sabor.
\end{abstract}

\section{INTRODUÇÃO}

Os elementos residuais de produtos de origem vegetal, constituídos por cascas, sementes, ramas, bagaços, dentre outros, são fontes de proteínas, fibras, óleos e enzimas e podem ser empregados para utilização humana na elaboração de produtos com maior valor agregado, reservando-se os detritos para a fabricação de ração animal e adubos (Garmus et al., 2009). Na fabricação do suco de abacaxi, de acordo com Waughon \& Pena (2006), é descartado, além da casca e coroa, parte da polpa, potencialmente rica em fibras, a qual poderia ser aproveitada na elaboração de novos produtos, devido, principalmente, aos diversos benefícios à saúde humana, obtidos pela ingestão de fibras.

Diversas são as formas de utilização e aproveitamento da casca de abacaxi. Uma delas, abordada por Marreiro et al. (2010), foi a aplicação deste resíduo, após ser seco em estufa a $60{ }^{\circ} \mathrm{C}$ por 5 horas, na elaboração de chá, abordando suas propriedades sensoriais e nutritivas. $\mathrm{O}$ autor, concluiu que o chá da casca do abacaxi representa uma alternativa de aproveitamento do resíduo e de fonte de 


\section{9 a 22 de outubro de 2014 \\ Florianópolis/SC}

nutrientes essenciais como vitamina $\mathrm{C}$, e que, por ter sido bem aceito sensorialmente por consumidores em potencial, é uma possibilidade para projeção em escala comercial.

A desidratação ou secagem de alimentos é a operação de remoção de água na forma de vapor por meio de vaporização térmica cujo objetivo principal é prolongar a vida útil dos alimentos pela redução de sua atividade de água. A secagem em leito fluidizado é uma técnica utilizada principalmente para materiais granulares e detém uma posição importante entre os métodos de secagem. Suas principais vantagens são as boas condições para a transferência de calor e massa, com a possibilidade de aplicação de outras fontes de energia e boa uniformidade do material no leito (Strumillo \& Kudra, 1930).

Assim, este trabalho aborda a obtenção de um co-produto de abacaxi por meio do estudo da secagem da casca do fruto para utilização como matéria prima na produção de chá com os objetivos de avaliar os efeitos da temperatura e velocidade do ar na secagem da casca de abacaxi em leito fluidizado e na aceitação sensorial do chá. Os resultados apresentados mostram que a principal variável que influência a secagem e a umidade final do produto é a temperatura do ar e que a aceitação sensorial do chá formulado com a casca não apresentou influência das variáveis do processo de secagem, apresentando na média aceitação moderada dos atributos sensoriais por parte dos consumidores.

\section{METODOLOGIA}

Os frutos de abacaxi foram adquiridos de um único produtor da região de São Francisco do Itabapoana - RJ entre os meses de agosto a novembro de 2013. O processamento dos frutos e obtenção do resíduo como matéria prima aconteceu de forma higiênica, seguindo os padrões de boas práticas de manipulação de alimentos. A casca foi removida dos frutos manualmente com uma faca de aço inox, cortada em cubos menores e triturada em multiprocessador (Philco, modelo All in one). A casca triturada foi armazenada em frações menores em sacos plásticos selados sob refrigeração. Previamente à secagem, uma fração do material foi lavada por três vezes em volume de água potável igual a sua massa, com o objetivo de reduzir o teor de sólidos solúveis totais que causava coesividade ao material. Após a lavagem, o material foi prensado manualmente, com auxílio de espremedor de batatas doméstico em alumínio para remoção do excesso de água. Em seguida, parte do material era separada para análises de caracterização química e outra parte, $700 \mathrm{~g}$, era encaminhada ao carregamento do leito do equipamento para o processo de secagem.

Os experimentos de secagem foram realizados em secador de leito fluidizado cilíndrico com fluxo de ar quente, seguindo planejamento fatorial a dois níveis $\left(2^{2}\right)$, em relação às variáveis independentes, temperatura $\left(70{ }^{\circ} \mathrm{C}\right.$ e $\left.90{ }^{\circ} \mathrm{C}\right)$ e velocidade do ar $(5 \mathrm{~m} / \mathrm{s}$ e $10 \mathrm{~m} / \mathrm{s})$, com três repetições no ponto central, perfazendo um total de 7 experimentos (Neto, Scarminio e Bruns, 2001), conforme apresentado na Tabela 1. Os experimentos de secagem foram realizados por 90 minutos. 
Tabela 1 - Representação do planejamento experimental com os níveis codificados e reais das variáveis independentes temperatura e velocidade de ar de entrada de secagem

\begin{tabular}{ccccc}
\hline \multicolumn{5}{c}{ Variáveis Independentes } \\
\hline Ensaios & Temperatura & Velocidade & Temperatura $\left({ }^{\circ} \mathbf{C}\right)$ & Velocidade $(\mathbf{m} / \mathbf{s})$ \\
\hline 1 & -1 & -1 & 70 & 8,0 \\
2 & 1 & -1 & 90 & 8,0 \\
3 & -1 & 1 & 70 & 10,0 \\
4 & 1 & 1 & 90 & 10,0 \\
5 & 0 & 0 & 80 & 9,0 \\
6 & 0 & 0 & 80 & 9,0 \\
7 & 0 & 0 & 80 & 9,0 \\
\hline
\end{tabular}

A análise estatística dos dados obtidos da secagem em leito fluidizado de casca de abacaxi seguiu a metodologia de superfície de resposta utilizando o programa Statistica ${ }^{\circledR}$, versão 5.5. As respostas avaliadas foram umidade e aceitação sensorial do chá com relação aos atributos impressão global, cor, sabor e aroma.

A determinação do teor de umidade das amostras foi realizada pelo método da AOAC (1995).

O pó para o preparo do chá foi obtido por trituração do produto seco, proveniente de cada condição de secagem, realizada em liquidificador (Philips Walita, Mod. RI2160) em rotação máxima por 60 segundos.

O preparo das infusões foi realizado de forma padronizada, com imersão do pó, em concentrações de $4 \mathrm{~g}$ de massa seca em $200 \mathrm{~mL}$ de água mineral aquecida a $100{ }^{\circ} \mathrm{C}$ e mantida por 10 minutos em recipiente tampado com plástico filme em banho-maria. As soluções foram então filtradas em filtro de papel $n^{\circ} 102$ diretamente em garrafas térmicas onde os produtos foram armazenados até o momento de serem servidas aos avaliadores.

Amostras dos sete ensaios dos chás em infusão tiveram a aceitação sensorial global (impressão global) avaliada, bem como com relação à cor, ao aroma e ao sabor, utilizando-se a escala hedônica estruturada de nove pontos (Meilgaard et al., 2007).

A avaliação procedeu-se em duas sessões, visando evitar fadiga sensorial. Em cada sessão, a apresentação das amostras foi realizada de forma sequencial, utilizando delineamento em blocos completos casualisados para sete amostras.

Todas as avaliações foram realizadas sob mesmas condições para todos os avaliadores, em cabines individuais equipadas com cuspideira, sob luz incandescente branca. As amostras foram servidas à temperatura de $80{ }^{\circ} \mathrm{C} \pm 3{ }^{\circ} \mathrm{C}$ em quantidade aproximada de $30 \mathrm{~mL}$, em copos descartáveis 
de $50 \mathrm{~mL}$, codificados com números aleatórios de três dígitos, acompanhadas de água para ingestão entre as amostras, colher descartável, açúcar e adoçante.

\section{RESULTADOS E DISCUSSÃO}

Os resultados do teste de aceitação indicam que os potenciais consumidores do chá de abacaxi gostaram de todas as formulações (Erro! Fonte de referência não encontrada.), uma vez que: a) as médias de aceitação sensorial de todas as amostras em todos os atributos hedônicos avaliados localizaram-se na região de aceitação, ou seja, com valores maiores ou iguais a 6 ("gostei ligeiramente"); e b) as médias para a impressão global localizaram-se próximas a 7, correspondente à categoria "gostei moderadamente", normalmente considerada boa aceitação em estudos com consumidores. Entretanto, os avaliadores gostaram mais da cor e do aroma das bebidas do que do sabor: as médias de aceitação da cor e do aroma foram todas superiores a 7, enquanto as médias observadas para o sabor, entre "gostei ligeiramente" e "moderadamente".

Tabela 2 - Médias da umidade final dos produtos secos e da aceitação sensorial das amostras de chá de abacaxi $(\mathrm{n}=63)$

\begin{tabular}{|c|c|c|c|c|c|c|}
\hline \multirow{2}{*}{\multicolumn{2}{|c|}{ Condição Real }} & \multirow{3}{*}{$\begin{array}{l}\text { Umidade } \\
\text { (\% b.u.) }\end{array}$} & \multicolumn{4}{|c|}{ Médias de Aceitação Sensorial $^{1}$} \\
\hline & & & \multirow{2}{*}{$\begin{array}{c}\text { Impressão } \\
\text { global }\end{array}$} & \multirow{2}{*}{ Cor } & \multirow{2}{*}{ Aroma } & \multirow{2}{*}{ Sabor } \\
\hline $\mathrm{T}\left({ }^{\circ} \mathrm{C}\right)$ & $\mathrm{v}(\mathrm{m} / \mathrm{s})$ & & & & & \\
\hline 70 & 8 & $10 \pm 2$ & 6,8 & 7,1 & 7,2 & 6,6 \\
\hline 70 & 10 & $8 \pm 2$ & 6,8 & 7,5 & 7,3 & 6,6 \\
\hline 90 & 8 & $3,4 \pm 0,2$ & 6,6 & 7,4 & 7,2 & 6,4 \\
\hline 90 & 10 & $3,1 \pm 0,3$ & 6,8 & 7,6 & 7,3 & 6,4 \\
\hline 80 & 9 & $5,0 \pm 0,5$ & 6,6 & 7,2 & 7,2 & 6,4 \\
\hline 80 & 9 & $5,3 \pm 0,3$ & 7,1 & 7,6 & 7,3 & 6,8 \\
\hline 80 & 9 & $6,3 \pm 0,7$ & 6,9 & 7,5 & 7,2 & 6,6 \\
\hline
\end{tabular}

T: Temperatura do ar de secagem; v: velocidade do ar de secagem; b.u.: base úmida; ${ }^{1} 1$ : desgostei extremamente; 2: desgostei muito; 3: desgostei moderadamente; 4: desgostei ligeiramente;

5: nem gostei/nem desgostei; 6: gostei ligeiramente; 7: gostei moderadamente; 8: gostei muito; 9: gostei extremamente.

Por meio da metodologia de superfície de resposta foi possível observar, com 95\% de confiança, que os atributos sensoriais hedônicos avaliados (impressão global, cor, aroma e sabor) do chá preparado a partir do produto seco não sofreram efeito significativo da temperatura e da velocidade do ar utilizados na secagem da casca de abacaxi (Tabela 3 ).

A umidade final (\% b.u.) sofreu efeito significativo $(\mathrm{p} \leq 0,05)$ apenas da temperatura do ar na secagem em leito fluidizado (Tabela 3). Como era esperado, o valor negativo do efeito indica que 
quanto maior é a temperatura aplicada ao processo, menor é a umidade final do produto. A umidade final da casca foi reduzida de $82 \%$ para valores médios de $9 \%, 5,5 \%$ e 3,3\% após a secagem em leito fluidizado a 80,70 e $60{ }^{\circ} \mathrm{C}$, respectivamente.

Tabela 3 - Estimativa dos efeitos para as respostas de umidade e dos atributos sensoriais hedônicos impressão global, cor, aroma e sabor do chá de abacaxi

\begin{tabular}{c|c|c|c|c|c|c|c|c|c|c}
\hline & \multicolumn{2}{|c|}{ Umidade $(\% \mathrm{bu})$} & \multicolumn{2}{c|}{ Imp. Global } & \multicolumn{2}{c|}{ Cor } & \multicolumn{2}{c|}{ Aroma } & \multicolumn{2}{c}{ Sabor } \\
\hline & Efeito & $p$ & Efeito & $p$ & Efeito & $p$ & Efeito & $P$ & Efeito & $p$ \\
\hline Média & $6,0128^{*}$ & $0,0018^{*}$ & $6,7929 *$ & $0,0002 *$ & $7,40571 *$ & $0,00009^{*}$ & $7,26857 *$ & $0,00001 *$ & $6,54714^{*}$ & $0,00015^{*}$ \\
$\left(\mathrm{X}_{1}\right)$ Temp. $\left({ }^{\circ} \mathrm{C}\right)$ & $5,8084 *$ & $0,0132 *$ & $-0,0950$ & 0,7480 & 0,12000 & 0,58711 & $-0,00500$ & 0,92308 & $-0,17000$ & 0,50671 \\
$\left(\mathrm{X}_{2}\right) \operatorname{Vel} . \mathrm{Ar}(\mathrm{m} / \mathrm{s})$ & $-1,1753$ & 0,2423 & 0,1250 & 0,6758 & 0,25000 & 0,31337 & 0,12500 & 0,11222 & 0,05000 & 0,83548 \\
$\mathrm{X}_{1} * \mathrm{X}_{2}$ & 0,9114 & 0,3376 & 0,0450 & 0,8776 & $-0,18000$ & 0,43768 & $-0,00500$ & 0,92308 & 0,00000 & 1,00000 \\
\hline
\end{tabular}

*Efeitos significativos a $95 \%$ de confiança

A partir dos coeficientes de regressão dos fatores significativos para a umidade final, com intervalo de confiança de $95 \%$ baseado no erro puro, obteve-se o modelo estatístico codificado da umidade da casca de abacaxi em função da temperatura do ar de secagem (Umidade $(\%$ Xb.u $)=$ $5,887-2,865$. T

$$
\text { Umidade }(\% \text { Xb.u })=5,887-2,865 . \mathrm{T}
$$

A significância do modelo expresso pela Equação 1 e de sua falta de ajuste foi verificada pela análise da variância (ANOVA) considerando intervalo de confiança de 95\%. Com isto, foi possível verificar que o modelo obtido para a umidade (\% Xb.u.) em função da temperatura do processo é preditivo e explica $96 \%\left(\mathrm{R}^{2}\right)$ da variação da resposta por meio do modelo.

\section{CONCLUSÕES}

Foi possível concluir ao final das secagens da casca de abacaxi em leito fluidizado, que com aumento da temperatura há redução significativa na umidade, ao nível de $95 \%$ de confiança. A aceitação sensorial dos atributos avaliados (impressão global, cor, aroma e sabor) do chá da casca seca de abacaxi não se alterou significativamente por efeito das variáveis estudadas a $95 \%$ de confiança.

Independente do tratamento utilizado na secagem da casca de abacaxi, os chás obtiveram aceitação sensorial similar, com médias próximas a "gostei moderadamente" com relação à impressão global, cor e aroma, e, entre "gostei ligeiramente" e "muito" com relação ao sabor.

\section{AGRADECIMENTOS}


Os autores gostariam de agradecer à FAPERJ pelo auxílio financeiro e a CAPES pela concessão da bolsa de mestrado.

\section{REFERÊNCIAS}

AOAC. Official Methods of Analysis. Association of Official Analytical Chemists, Washington, 1995.

GARMUS, T. T.; BEZERRA, J. R. M. V.; RIGO, M.; CÓRDOVA, K. R. V. Elaboração de biscoitos com adição de farinha de casca de batata (Solanum tuberosum L.). Rev. Bras. de Tecn. Agroind. Universidade Tecnológica Federal do Paraná - UTFPR Campus Ponta Grossa - Paraná - Brasil. v. 03, n. 02: p. 56-65, 2009.

MARREIRO, A. S. N.; AMORIN, M. M.; TEIXEIRA, P. R. S. Elaboração do chá do abacaxi (Ananas comosus-Bromeliaceae) e caracterização das propriedades físico-químicas e sensoriais. Rev. ACTA Tecnológica - Revista Científica - ISSN 1982-422X, Vol. 5, número 1, 2010.

MEILGAARD, M.; CIVILlE, G. V.; CARR, B. T. Sensory Evaluation Techniques. $4^{\mathrm{a}}$ ed. Boca Raton: CRC Press, 448 p, 2007.

NETO, B. B.; SCARMINIO, I. S.; BRUNS, R. E. Como Fazer Experimentos: Pesquisa e Desenvolvimento na Ciência e na Indústria. (Coleção Livros Textos). $1^{\mathrm{a}}$ ed. Campinas: EDUNICAMP, 2001.

STRUMILlO, C.; KUDRA, T. Drying: Principles, applications and design. Institute of Chemical Engineering. Lodz Technical University, Poland. v.3, 1930.

WAUGHON, T. G. M.; PENA, R. S. Estudo da secagem da fibra residual do abacaxi. Alim. $e$ Nutrição. Araraquara, v.17, n.4, p.373-379, 2006. 